\title{
Once-weekly vs. twice-weekly carfilzomib dosing in a subgroup of Japanese relapsed and refractory multiple myeloma patients from a randomized phase 3 trial (A.R.R.O.W.) and comparison with ENDEAVOR
}

\author{
Naoki Takezako ${ }^{1} \cdot$ Hirohiko Shibayama ${ }^{2} \cdot$ Hiroshi Handa $^{3}$. Shotaro Hagiwara ${ }^{4}$ Shuji Ozaki ${ }^{5} \cdot K$ Kenshi Suzuki ${ }^{6}$. \\ Hiroshi Kosugi ${ }^{7} \cdot{\text { Masaki } \mathrm{Ri}^{8} \cdot \text { Isamu Sugiura }^{9} \cdot \text { Ilseung } \text { Choi }^{10} \cdot \text { Toshihiro Miyamoto }^{11} \text {. Shinsuke lida }}^{8}$
}

Received: 29 June 2020 / Revised: 26 August 2020 / Accepted: 24 September 2020 / Published online: 10 October 2020

(c) Japanese Society of Hematology 2020

\begin{abstract}
A.R.R.O.W. evaluated the superiority of once-weekly carfilzomib plus dexamethasone (Kd) 20/70 mg/m² vs. twice-weekly Kd $20 / 27 \mathrm{mg} / \mathrm{m}^{2}$ based on progression-free survival (PFS) in relapsed and/or refractory multiple myeloma patients. Forty Japanese patients (once-weekly arm, $n=26$; twice-weekly arm, $n=14$ ) were randomized in A.R.R.O.W. In the Japanese subgroup of A.R.R.O.W., median PFS was 14.8 months (95\% confidence interval [CI], 7.5-not evaluable [NE]) and 9.7 months (95\% CI, 3.8-NE) in the once- and twice-weekly arms, respectively. The overall response rate (ORR) was 73.1\% (19/26; 95\% CI, $52.2-88.4)$ and $57.1 \%(8 / 14 ; 95 \%$ CI, 28.9-82.3) in each arm. The adverse events (AEs) incidence was $100 \%$ in both arms. Grade $\geq 3$ AE incidence was $80.8 \%$ (21/26) and 78.6\% (11/14) in each arm. Two fatal treatment-related AEs (acute lung injury and acute respiratory distress syndrome) occurred in the once-weekly arm. In exploratory unadjusted analyses of A.R.R.O.W. (once-weekly Kd 20/70 mg/m²) vs. ENDEAVOR (twice-weekly Kd 20/56 mg/m²), median PFS was 14.8 months vs. NE due to not yet being reached, and ORR was $73.1 \%$ (19/26) vs. $42.9 \%$ (3/7). In the Japanese subgroup, once-weekly Kd tended to improve ORR vs. twice-weekly Kd. Results from A.R.R.O.W. tended to be consistent with results from ENDEAVOR.
\end{abstract}

Keywords Carfilzomib $\cdot$ Japanese $\cdot$ Kyprolis $\cdot$ Once-weekly $\cdot$ Relapsed and refractory multiple myeloma

\section{Introduction}

Some results of this study were previously published: Moreau $\mathrm{P}$, Mateos MV, Berenson JR, Weisel K, Lazzaro A, Song K, et al. Once weekly versus twice weekly carfilzomib dosing in patients with relapsed and refractory multiple myeloma (A.R.R.O.W.): interim analysis results of a randomised, phase 3 study. Lancet Oncol. $2018 \mathrm{Jul} ; 19(7): 953-964$.

Electronic supplementary material The online version of this article (https://doi.org/10.1007/s12185-020-03013-6) contains supplementary material, which is available to authorized users.

Naoki Takezako

ntakezak@tdmc.hosp.go.jp

1 National Hospital Organization Disaster Medical Center, 3256 Midori, Tachikawa, Tokyo 190-0014, Japan

2 Osaka University Graduate School of Medicine, Suita, Japan

3 Gunma University Graduate School, Maebashi, Japan

4 Tokyo Women's University, Tokyo, Japan

5 Tokushima Prefectural Central Hospital, Tokushima, Japan

Multiple myeloma (MM) comprises approximately $10 \%$ of all hematological malignancies. In Japan, the annual incidence and 5-year prevalence rates of MM were reported to be 1.3-5.4 and 9.7 per 100,000 persons, respectively [1]. Given the better understanding of the disease and the advent of new treatments during the past decades, the overall survival (OS) of patients with MM has remarkably increased

6

10

Tospital Organization Kyushu Cancer Center, Fukuoka, Japan

11 Kyushu University Hospital, Fukuoka, Japan 
[2]. However, despite these advances and the increase in OS, MM remains an incurable disease, the morbidity of MM has increased in Asia [3], and treatment options that provide survival benefits are needed.

Carfilzomib (Kyprolis®, Amgen, Thousand Oaks, CA, USA) is a second-generation epoxyketone proteasome inhibitor [4]. It is highly selective and preferentially inhibits the proteasome subunit, CT-L/LMP7 [5]. Carfilzomib differs from bortezomib in that it binds to a different site on the proteasome, and that it binds irreversibly. Carfilzomib is indicated for the treatment of relapsed and refractory multiple myeloma (RRMM) in combination with dexamethasone (once-weekly carfilzomib $20 / 70 \mathrm{mg} / \mathrm{m}^{2}$ or twice-weekly $20 / 56 \mathrm{mg} / \mathrm{m}^{2}$; administered as a 30 -min infusion), or lenalidomide (Revlimid®, Celgene Corp., Summit, NJ, US) plus dexamethasone (KRd) (carfilzomib $20 \mathrm{mg} / \mathrm{m}^{2}$ starting dose that can be escalated to $27 \mathrm{mg} / \mathrm{m}^{2}$ twice weekly and administered as a 10-min infusion) in both the United States [4] and Japan [6].

The efficacy of carfilzomib plus dexamethasone $(\mathrm{Kd})$ in improving OS was established in the phase 3 ENDEAVOR trial $[7,8]$. This trial compared carfilzomib head to head with bortezomib (Velcade ${ }^{\mathrm{TM}}$ Millennium Pharmaceuticals, Cambridge, MA, USA) plus dexamethasone (Vd). In this trial, Kd (twice-weekly $\mathrm{Kd} 20 / 56 \mathrm{mg} / \mathrm{m}^{2}$ ) significantly increased the median OS compared with $\mathrm{Vd}$ (47.6 months in the Kd group vs. 40.0 months in the bortezomib group [hazard ratio (HR) 0.791 (95\% confidence interval [CI] $0.648-0.964)$ ], one-sided $p=0.010$ ) [8].

In a Japanese phase 1 dose-escalation study of carfilzomib monotherapy $\left(20 \mathrm{mg} / \mathrm{m}^{2}\right.$ in Cycle 1 , Days $1-2$, followed by 45 or $56 \mathrm{mg} / \mathrm{m}^{2}$ ), the overall response rates (ORR) of the $20 / 45 \mathrm{mg} / \mathrm{m}^{2}$ and $20 / 56 \mathrm{mg} / \mathrm{m}^{2}$ cohorts were $66.7 \%$ and $50 \%$, respectively [9]. In a phase $1 / 2$ trial of carfilzomib monotherapy, the ORR, median progression-free survival (PFS), and median OS at a dose of $20 / 27 \mathrm{mg} / \mathrm{m}^{2}(20 \mathrm{mg} /$ $\mathrm{m}^{2}$ in Cycle 1, Days 1-2, and then escalated to $27 \mathrm{mg} / \mathrm{m}^{2}$ ) were $22.5 \%, 5.1$ months, and 22.9 months, respectively [10]. The CHAMPION-1 study [11] and a Japanese phase 1 trial [12] assessed the maximum tolerated dose of once-weekly $\mathrm{Kd} 20 / 70 \mathrm{mg} / \mathrm{m}^{2}\left(20 \mathrm{mg} / \mathrm{m}^{2}\right.$ in Cycle 1 , and escalated up to once-weekly $70 \mathrm{mg} / \mathrm{m}^{2}$ ). The ORRs were $77 \%$ and $83.3 \%$, respectively, and in both studies, the dose of $20 / 70 \mathrm{mg} / \mathrm{m}^{2}$ was well-tolerated.

The A.R.R.O.W. study [13] is a multicenter, open-label phase 3 trial that tested the hypothesis that once-weekly $\mathrm{Kd} 20 / 70 \mathrm{mg} / \mathrm{m}^{2}$ is superior to twice-weekly $\mathrm{Kd} 20 / 27 \mathrm{mg} /$ $\mathrm{m}^{2}$ in terms of PFS. When this study was designed, $\mathrm{Kd}$ $20 / 70 \mathrm{mg} / \mathrm{m}^{2}$ was one of the standards of care as thirdline therapy for patients with RRMM, and the results of the ENDEAVOR study were not yet available. The results indicated that once-weekly $\mathrm{Kd} 20 / 70 \mathrm{mg} / \mathrm{m}^{2}$ significantly prolonged PFS compared with twice-weekly Kd 20/27 mg/ $\mathrm{m}^{2}$, and both treatment schedules had comparable safety. Herein, we describe the results of the Japanese subgroup of the A.R.R.O.W. study [13]. To date, no clinical studies have compared once-weekly $\mathrm{Kd} 20 / 70 \mathrm{mg} / \mathrm{m}^{2}$ with twiceweekly $\mathrm{Kd} 20 / 56 \mathrm{mg} / \mathrm{m}^{2}$. To compare the outcomes of onceweekly Kd 20/70 mg/m² vs. twice-weekly Kd 20/56 mg/ $\mathrm{m}^{2}$, we compared data from subjects from the A.R.R.O.W. study who were treated with once-weekly Kd 20/70 mg/m² with that of subjects from the ENDEAVOR study who were treated with twice-weekly $\mathrm{Kd} 20 / 56 \mathrm{mg} / \mathrm{m}^{2}$ [7, 8]. Owing to key differences in the eligibility of subjects from the ENDEAVOR and A.R.R.O.W. studies in terms of prior number of therapies, refractoriness to the most recent therapy, and prior use of a proteasome inhibitor and immunomodulatory drugs, we conducted an exploratory unadjusted analysis using subjects from the ENDEAVOR study whose criteria met that of both the overall and Japanese populations of the A.R.R.O.W. study.

\section{Materials and methods}

\section{Patients}

Detailed inclusion and exclusion criteria for the A.R.R.O.W. study have been previously published [13]. Briefly, eligible subjects were men and women $\geq 18$ years of age with RRMM, who had received two to three prior regimens, including a proteasome inhibitor and an immunomodulatory drug. Subjects were required to be refractory to the most recent therapy (including bortezomib or ixazomib) and have measurable disease defined by $\geq 1$ of the following (assessed within 21 days before randomization): serum M-protein $\geq 0.5 \mathrm{~g} / \mathrm{dL}$, urine M-protein $\geq 200 \mathrm{mg} / 24 \mathrm{~h}$, or in subjects without detectable serum or urine M-protein, serum-free light chain (SFLC) $\geq 100 \mathrm{mg} / \mathrm{L}$ (involved light chain) and an abnormal serum kappa lambda ratio (SFLC kappa lambda ratio $<0.22$ or $>1.52$ ).

Key exclusion criteria were as follows: having received cytotoxic chemotherapy 28 days or radiotherapy 7 days prior to randomization; presence of Waldenström macroglobulinemia; MM of the immunoglobulin M subtype; polyneuropathy, organomegaly, endocrinopathy, monoclonal gammopathy, and skin changes syndrome; plasma cell leukemia; myelodysplastic syndrome; history of or current amyloidosis; second malignancy in the past 5 years; grade 3 or worse neuropathy in the 14 days before randomization; active infection; or severe cardiac disease.

Ethical approval by the institutional review boards was obtained, and the study was conducted in accordance with the International Council for Harmonisation Good Clinical Practice regulations/guidelines and the Declaration of Helsinki. All patients provided written informed consent. The 
A.R.R.O.W. study was registered at ClinicalTrials.gov under the identifier NCT02412878.

\section{Study design, treatments, and measures}

The details of the study design have been published [13]. The A.R.R.O.W. study was a randomized, open-label, phase 3 trial. Eligible subjects were randomly assigned in a 1:1 ratio through an interactive voice response system or interactive web response system to receive either once-weekly $\mathrm{Kd} 20 / 70 \mathrm{mg} / \mathrm{m}^{2}$ or twice-weekly $\mathrm{Kd} 20 / 27 \mathrm{mg} / \mathrm{m}^{2}$. Eligible subjects were stratified at the time of randomization based on the International Staging System (stage 1 vs. stages 2 or 3 ), refractory to bortezomib treatment (yes vs. no), and age ( $<65$ vs. $\geq 65$ years) and were randomly assigned to treatment on a blocked randomization scheme.

Kd was administered in 28-day cycles. All cycles started 28 days ( \pm 2 days) after the start of the previous cycle. The once-weekly $\mathrm{Kd}$ arm received carfilzomib (30 min intravenous infusion) on days 1,8 , and 15 of all cycles $(20 \mathrm{mg} /$ $\mathrm{m}^{2}$ [Cycle 1, Day 1]; $70 \mathrm{mg} / \mathrm{m}^{2}$ thereafter: $\mathrm{Kd} 20 / 70 \mathrm{mg} /$ $\mathrm{m}^{2}$ ). The twice-weekly Kd arm received carfilzomib (10 min intravenous infusion) on Days 1, 2, 8, 9, 15, and 16 (20 mg/ $\mathrm{m}^{2}$ Cycle 1, Days 1-2; $27 \mathrm{mg} / \mathrm{m}^{2}$ thereafter: Kd 20/27 mg/ $\mathrm{m}^{2}$ ).

Dexamethasone $40 \mathrm{mg}$ was administered for at least 30 min on Days 1, 8, and 15 in both treatment arms. Dexamethasone on Day 22 was taken orally, whenever possible, and was only administered during Cycles 1 to 9. Treatment continued until disease progression or unacceptable toxic effects. Dose reductions of carfilzomib were permitted to manage adverse events (AEs). Antiviral prophylaxis (valacyclovir or an equivalent antiviral agent) was recommended to prevent herpes zoster reactivation during treatment and a protonpump inhibitor was recommended to prevent peptic ulcer disease.

To assess response and disease progression, we used modified versions of the International Myeloma Working Group-Uniform Response Criteria [14] and the Consensus recommendations of the International Myeloma Workshop Consensus Panel 1 [15]. Hematological and serum chemistry assessments were conducted at a central laboratory.

\section{Endpoints}

\section{Efficacy}

The primary study endpoint of the A.R.R.O.W. study was PFS (defined as the time from randomization until disease progression or death due to any cause), which was compared between arms in the intent-to-treat population. The secondary endpoints were ORR (defined as the proportion of patients who achieved a partial response, very good partial response, complete response [CR], or stringent complete response [sCR] according to International Myeloma Working Group Uniform Response Criteria), best overall response, duration of overall response, clinical benefit rate (CBR), and OS (defined as the time from randomization to death due to any cause). To compare two dosing regimens (onceweekly $\mathrm{Kd} 20 / 70 \mathrm{mg} / \mathrm{m}^{2}$ and twice-weekly Kd 20/56 mg/ $\mathrm{m}^{2}$ ), we conducted an exploratory unadjusted analysis using data from a subgroup of patients from the A.R.R.O.W. study who were treated with once-weekly $\mathrm{Kd} 20 / 70 \mathrm{mg} / \mathrm{m}^{2}$ and a subgroup of patients from the ENDEAVOR study who were treated with twice-weekly $\mathrm{Kd} 20 / 56 \mathrm{mg} / \mathrm{m}^{2}$. The following key inclusion criteria that were similar between the two studies were identified: patients who had two to three prior therapies, were refractory to the most recent therapy and had prior use of a proteasome inhibitor and immunomodulatory drugs. Comparisons were made between the overall populations of the A.R.R.O.W. (once-weekly Kd $20 / 70 \mathrm{mg} / \mathrm{m}^{2}$ ) and ENDEAVOR (twice-weekly $\mathrm{Kd} 20 / 56 \mathrm{mg} / \mathrm{m}^{2}$ ) studies; the overall populations of A.R.R.O.W. and ENDEAVOR who met the above criteria; and the Japanese subgroups of A.R.R.O.W. and ENDEAVOR who met the above criteria.

\section{Safety}

Safety endpoints of the A.R.R.O.W. study were AEs and any abnormalities in vital signs, general laboratory tests (blood chemistry, hematology, coagulation, and urinalysis), and 12-lead electrocardiography.

AEs were recorded for at least 30 days after the last administered dose and were graded according to the National Cancer Institute Common Terminology Criteria for Adverse Events (version 4.03).

\section{Statistical methods}

Details of the statistical methods, definition of pre-planned analysis populations, and primary/secondary analyses have already been described in the interim report of the ARROW study [13]. For PFS and OS, the median timetoevent per each treatment arm was derived using the Kaplan-Meier method. The duration of response was summarized descriptively using the Kaplan-Meier method in patients who achieved at least a partial response. In this A.R.R.O.W. study, the log-rank test was used for between-group comparisons (once weekly vs. twice weekly arms), and the corresponding HR and $95 \%$ CI were estimated using a Cox proportional hazards model stratified by the randomization stratification factors. The Cochran-Mantel-Haenszel test was used to analyze stratified binary data (ORR).

The present analyses were subgroup analyses of the intent-to-treat population and not powered nor adjusted for multiplicity. We conducted an exploratory unadjusted 
analysis comparing data between the overall populations of the A.R.R.O.W. (once-weekly Kd $20 / 70 \mathrm{mg} / \mathrm{m}^{2}$ ) and ENDEAVOR (twice-weekly Kd $20 / 56 \mathrm{mg} / \mathrm{m}^{2}$ ) studies, and between the overall populations of A.R.R.O.W. and ENDEAVOR and the Japanese subgroups of A.R.R.O.W. and ENDEAVOR who had received two to three prior therapies, were refractory to the most recent therapy, and had received prior proteasome inhibitor and immunomodulatory drugs, and compared these subgroups numerically. All statistical analyses were conducted using SAS software version 9.3 (SAS Institute Inc., Cary, NC, USA).

\section{Results}

\section{Patients}

Patient disposition is shown in Fig. 1. Of the 47 Japanese patients screened, 40 were randomly assigned to the treatment arms: 26 patients were assigned to the once-weekly arm and 14 patients to the twice-weekly arm. All patients in each arm received $\mathrm{Kd}$. In the once-weekly arm, 18 patients discontinued the study drug: nine discontinued for AEs; seven discontinued for disease progression, and one patient each discontinued for subject request and physician decision. In the twice-weekly arm, 10 patients discontinued the study drug: eight discontinued for disease progression and two for AEs.

In the Japanese subgroup, patients in the once-weekly and twice-weekly arms were generally comparable in terms of demographic and disease characteristics (Table 1). Overall, as well as in both arms, slightly more than half of the patients were male (53.8\% and $57.1 \%$, respectively). Overall, patients had a median age of $67.0(35,80)$ years. In the once-weekly arm vs. twice-weekly arm, a larger proportion of patients ( $46.2 \%$ vs. $35.7 \%$ ) were between 65 and 74 years of age, while in the twice-weekly arm vs. once-weekly arm, a larger proportion of patients $(42.9 \%$ vs. $26.9 \%)$ were between 18 and 64 years of age. Over $60 \%$ of patients overall and in both arms had an Eastern Cooperative Oncology Group Performance Status of 0. In the once-weekly arm, $61.5 \%$ of patients had an unknown risk determined by fluorescence in situ hybridization, followed by $19.2 \%$ each for high and standard risk, while in the twice-weekly arm, half of the patients had an unknown risk status, but $28.6 \%$ were at high risk, and $21.4 \%$ were at standard risk. All patients had received either two or three prior treatment regimens. Patients in the once-weekly arm received a median of 2.5 prior treatments, and those in the twice-weekly arm received a median of 2.4 prior treatments. Prior treatment regimens included bortezomib (100\%), lenalidomide (92.5\%), or thalidomide (27.5\%). All patients were refractory to prior systemic treatment. The demographic and baseline disease characteristics of the overall population of the A.R.R.O.W. and ENDEAVOR studies are shown in Supplementary Table 1.

In the Japanese subgroup of the A.R.R.O.W. study, the once-weekly arm had a mean $\mathrm{Kd}$ treatment duration of 43.6 weeks (median 55.8 [2.1, 81.1] weeks) and received a mean of 11.4 cycles (median $14.0[1,20]$ cycles) and a

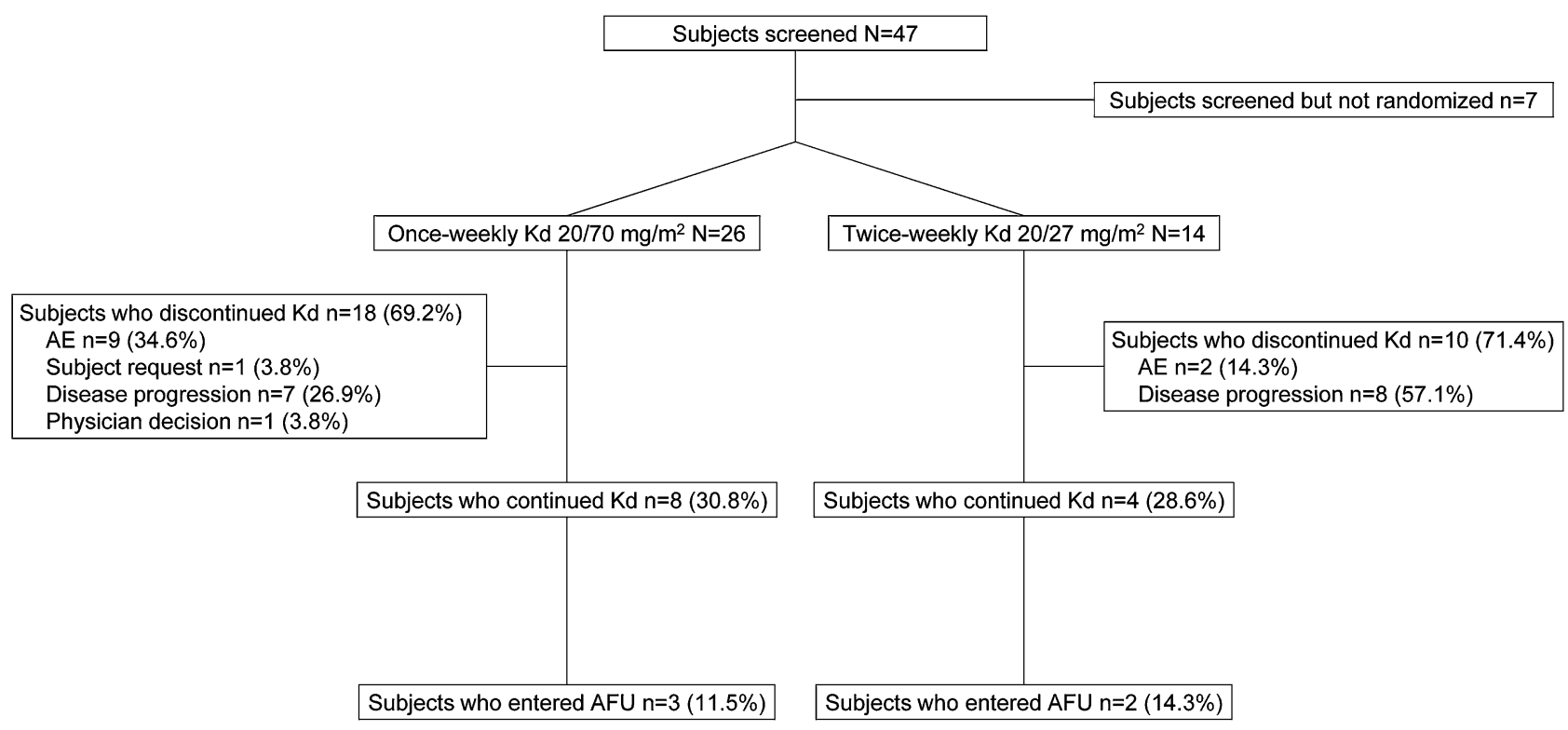

Fig. 1 Patient disposition of the Japanese subgroup from A.R.R.O.W. $A E$ adverse event, $A F U$ active follow-up, $K d$ carfilzomib (kyprolis) plus dexamethasone 
Table 1 Demographic and baseline disease characteristics of the Japanese subgroup of the A.R.R.O.W. study

\begin{tabular}{|c|c|c|c|}
\hline & $\begin{array}{l}\text { Once-weekly } \\
\text { Kd 20/70 mg/m } 2 \\
(N=26) \\
n(\%)\end{array}$ & $\begin{array}{l}\text { Twice-weekly } \\
\mathrm{Kd} 20 / 27 \mathrm{mg} / \mathrm{m}^{2} \\
(N=14) \\
n(\%)\end{array}$ & $\begin{array}{l}\text { Total } \\
(N=40) \\
n(\%)\end{array}$ \\
\hline \multicolumn{4}{|l|}{ Sex } \\
\hline Male & $14(53.8)$ & $8(57.1)$ & $22(55.0)$ \\
\hline Female & $12(46.2)$ & $6(42.9)$ & $18(45.0)$ \\
\hline \multicolumn{4}{|l|}{ Age (years) } \\
\hline Median (min, max) & $68.0(45,80)$ & $65.5(35,79)$ & $67.0(35,80)$ \\
\hline $18-64$ years & $7(26.9)$ & $6(42.9)$ & $13(32.5)$ \\
\hline 65-74 years & $12(46.2)$ & $5(35.7)$ & $17(42.5)$ \\
\hline 75-84 years & $7(26.9)$ & $3(21.4)$ & $10(25.0)$ \\
\hline \multicolumn{4}{|l|}{$E C O G P S$} \\
\hline 0 & $16(61.5)$ & $9(64.3)$ & $25(62.5)$ \\
\hline 1 & $10(38.5)$ & $5(35.7)$ & $15(37.5)$ \\
\hline \multicolumn{4}{|l|}{ ISS stage at baseline } \\
\hline Stage 1 & $13(50.0)$ & $12(85.7)$ & $25(62.5)$ \\
\hline Stage 2 & $8(30.8)$ & $1(7.1)$ & $9(22.5)$ \\
\hline Stage 3 & $5(19.2)$ & $1(7.1)$ & $6(15.0)$ \\
\hline \multicolumn{4}{|l|}{ Risk group as determined by fluorescent in situ hybridization } \\
\hline High risk & $5(19.2)$ & $4(28.6)$ & $9(22.5)$ \\
\hline Loss of $\mathrm{p}$ arm of chromosome $17^{\mathrm{a}}$ & $2(7.7)$ & $2(14.3)$ & $4(10.0)$ \\
\hline Translocation $(4 ; 14)^{\mathrm{a}}$ & $3(11.5)$ & $3(21.4)$ & $6(15.0)$ \\
\hline Translocation $(14 ; 16)^{\mathrm{a}}$ & $2(7.7)$ & $0(0.0)$ & $2(5.0)$ \\
\hline Standard risk ${ }^{\mathrm{b}}$ & $5(19.2)$ & $3(21.4)$ & $8(20.0)$ \\
\hline Unknown & $16(61.5)$ & $7(50.0)$ & $23(57.5)$ \\
\hline Total number of prior regimens, mean (SD) & $2.5(0.5)$ & $2.4(0.5)$ & $2.5(0.5)$ \\
\hline \multicolumn{4}{|l|}{ Refractory status to last prior systemic therapy } \\
\hline Refractory & $26(100)$ & $14(100)$ & $40(100)$ \\
\hline \multicolumn{4}{|l|}{ Prior regimen } \\
\hline Bortezomib & $26(100.0)$ & $14(100.0)$ & $40(100.0)$ \\
\hline Lenalidomide & $25(96.2)$ & $12(85.7)$ & $37(92.5)$ \\
\hline Refractory to any prior lenalidomide-including regimen & $20(76.9)$ & $12(85.7)$ & $32(80.0)$ \\
\hline Not refractory to any prior lenalidomide-including regimen & $5(19.2)$ & $0(0.0)$ & $5(12.5)$ \\
\hline Thalidomide & $6(23.1)$ & $5(35.7)$ & $11(27.5)$ \\
\hline Refractory to any prior thalidomide-including regimen & $2(7.7)$ & $2(14.3)$ & $4(10.0)$ \\
\hline
\end{tabular}

$K d$ carfilzomib (Kyprolis) plus dexamethasone, ECOG PS Eastern Cooperative Oncology Group Performance Status, ISS International Staging System, $K$ carfilzomib, $S D$ standard deviation

${ }^{a}$ Genetic subtypes were determined by each study site using their individual cut-off values

${ }^{\mathrm{b}}$ Standard risk was defined as no high-risk genetic alterations described above were detected in the bone marrow

mean cumulative dose of $2130.0 \mathrm{mg} / \mathrm{m}^{2}$ (median 2558.6 [133.2, 4287.3] mg/m²). The twice-weekly arm had a mean Kd treatment duration of 40.1 (median 37.3 [7.9, 78.4] weeks) weeks and received a mean of 10.5 cycles (median $9.5[3,20]$ cycles) and a mean cumulative dose of $1592.4 \mathrm{mg} / \mathrm{m}^{2}$ (median 1415.8 [364.6, 3140.7] mg/m²).

\section{Efficacy results of the Japanese subgroup of the A.R.R.O.W. study}

The median PFS was 14.8 (95\% CI 7.5, not evaluable [NE]) months in the once-weekly arm and 9.7 (95\% CI 3.8, NE) months in the twice-weekly arm (Fig. 2a). The HR of 


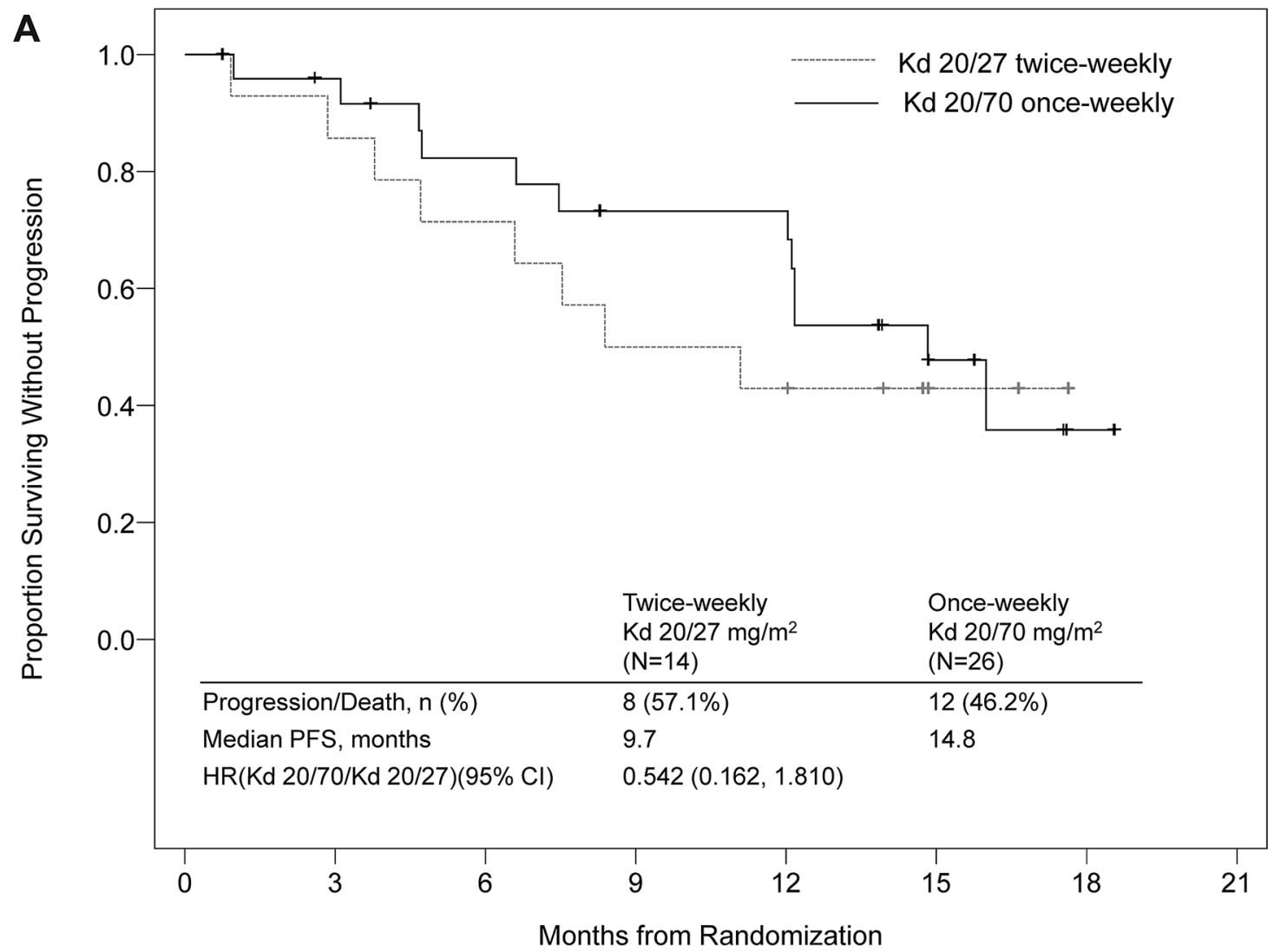

Number of Subjects at Risk:

$\begin{array}{llllccccc}\text { Kd 20/27 } & 14 & 12 & 10 & 7 & 6 & 2 & 0 & \\ \text { Kd 20/70 } & 26 & 22 & 18 & 15 & 15 & 6 & 1 & 0\end{array}$

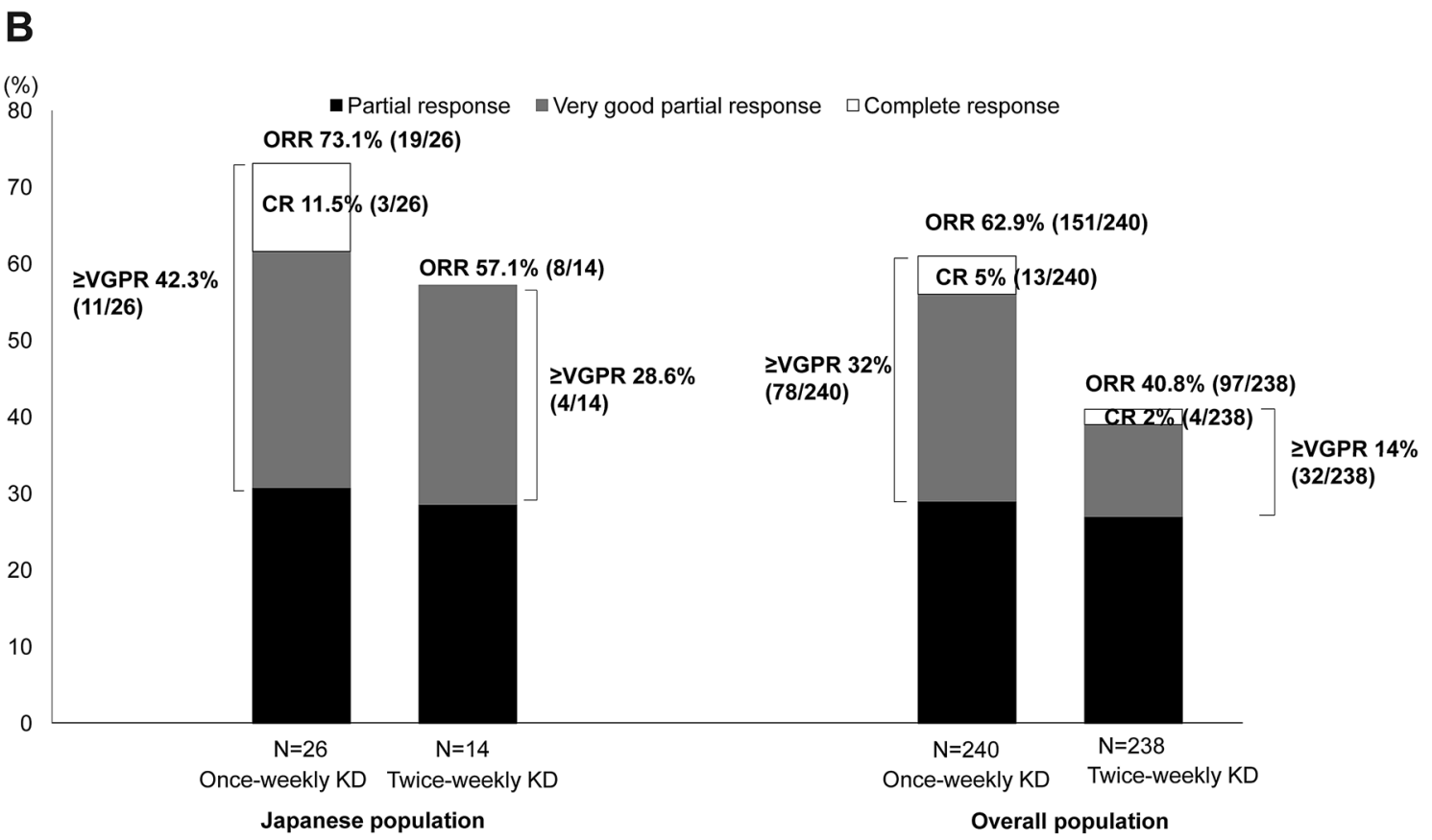


4Fig. 2 a Kaplan-Meier curve comparing PFS in the Kd once-weekly and $\mathrm{Kd}$ twice-weekly dosing arms of the Japanese subgroup from A.R.R.O.W. $C I$ confidence interval, $K d$ carfilzomib (Kyprolis) plus dexamethasone, $H R$ hazard ratio, $P F S$ progression-free survival. b Comparison of overall response rates in the overall population and Japanese subgroup from A.R.R.O.W. $C R$ complete response, $K d$ carfilzomib (Kyprolis) plus dexamethasone, ORR overall response rate, $V G P R$ very good partial response

progression or death for the once-weekly vs. twice-weekly arm was 0.542 (95\% CI 0.162, 1.810).

Table 2 provides a summary of the efficacy measures. Three of 26 patients in the once-weekly arm (11.5\%) and none of 14 patients in the twice-weekly arm achieved CR, while no patients in either arm achieved sCR. The ORR was $73.1 \%(19 / 26)$ in the once-weekly arm, and $57.1 \%$ (8/14) in the twice-weekly arm (Fig. 2B). The percentage of patients with very good partial response or better was $42.3 \%(11 / 26)$ in the once-weekly arm and $28.6 \%(4 / 14)$ in the twice-weekly arm. The median duration of response was $15.1(11.1, \mathrm{NE})$ months in the once-weekly arm and NE $(2.8, \mathrm{NE})$ months in the twice-weekly arm. The CBR was $84.6 \%(22 / 26)$ in the once-weekly arm and $57.1 \%(8 / 14)$ in the twice-weekly arm. OS was NE in both arms (Table 2).

\section{Exploratory analysis comparing the efficacy results from A.R.R.O.W. and ENDEAVOR}

We conducted an exploratory analysis comparing the efficacy results (Table 3 ) between (i) the overall populations of A.R.R.O.W. (once-weekly Kd 20/70 mg/m²) and ENDEAVOR (twice-weekly Kd 20/56 mg/m²); (ii) the overall populations of A.R.R.O.W. and ENDEAVOR who met the following criteria: had two to three prior therapies, were refractory to the most recent therapy and had prior use of a proteasome inhibitor and immunomodulatory drugs; and (iii) the Japanese subgroups of A.R.R.O.W. and ENDEAVOR who met the above criteria. The median PFS of the overall population of A.R.R.O.W. was 11.3 months, and that of the overall population of ENDEAVOR was 18.7 months. For the overall population in A.R.R.O.W. and ENDEAVOR who met the above criteria, the PFS was 11.2 months and 7.5 months, respectively, while for the Japanese subgroups from A.R.R.O.W. and ENDEAVOR who met the above criteria, the median PFS was 14.8 months and NE, respectively. The median ORR of the overall populations of A.R.R.O.W. was $63.8 \%(153 / 240)$, and that of the overall population of ENDEAVOR was $76.9 \%$ (357/464). For the overall population in A.R.R.O.W. and ENDEAVOR who met the above criteria, the ORR was $63.3 \%$ (150/237) and $44.3 \%$ (31/70) respectively, while for the Japanese subgroups from A.R.R.O.W. and ENDEAVOR who met the above criteria, the ORR was $73.1 \%(19 / 26)$ and $42.9 \%$ (3/7), respectively.

\section{Safety and tolerability}

In the Japanese subgroup of the A.R.R.O.W study, the incidence of AEs of any grade was $100 \%$ in both arms, with $80.8 \%(21 / 26)$ of grade $\geq 3$ AEs in the once-weekly arm and $78.6 \%(11 / 14)$ in the twice-weekly arm. Discontinuation of carfilzomib was attributable to AEs in $34.6 \%$ $(9 / 26)$ of the cases in the once-weekly arm and $14.3 \%$ $(2 / 14)$ in the twice-weekly arm. These AEs leading to discontinuation in the once-weekly arm were thrombotic microangiopathy (TMA), cardiac failure, cardiac failure acute ( 2 patients), cardiac failure congestive, pyrexia, pneumonia haemophilus, ejection fraction decreased, blood creatinine increased, C-reactive protein increased, acute lung injury (ALI; 2 patients), acute respiratory distress syndrome (ARDS), and hypertension. Those in the twice-weekly arm were cardiac failure and myelodysplastic syndrome. The two AEs observed in $\geq 2$ patients in the Japanese subgroup, cardiac failure acute and ALI, were not observed in other patients in the overall population in the once-weekly arm.

The incidence of treatment-related AEs was $92.3 \%$ $(24 / 26)$ in the once-weekly arm and $92.9 \%(13 / 14)$ in the twice-weekly arm (Table 4). There were two fatal treatmentrelated AEs, ALI and ARDS, both of which occurred in the once-weekly arm. Regarding the ALI case, this AE occurred during Cycle 18 (Day 484). Detailed information on the case could not be obtained. In the ARDS case, the AE occurred during Cycle 2 (Day 55). This patient had pneumonia secondary to influenza before developing ARDS.

The incidences of serious AEs were 61.5\% (16/26) and $28.6 \%$ (4/14) in the once-weekly and twice-weekly Kd arms, respectively. Serious AEs that occurred with a frequency greater than $5 \%$ in the once-weekly $\mathrm{Kd}$ arm were tumor lysis syndrome $(11.5 \%, 3 / 26)$, cardiac failure acute $(7.7 \%$, $2 / 26)$, pneumonia (7.7\%), and acute lung injury (7.7\%). In the twice-weekly $\mathrm{Kd}$ arm, serious AEs that occurred with a frequency greater than 5\% were cardiac failure $(7.1 \%, 1 / 14)$, cholecystitis acute $(7.1 \%)$, pneumonia $(7.1 \%)$, osteomyelitis (7.1\%), and acute kidney injury (7.1\%).

Table 5 shows the AEs overall and grade 3 or higher that occurred in more than $10 \%$ of subjects. Of any grade, the AEs with the highest frequency in the once-weekly and twice-weekly arms were platelet count decreased $(38.5 \%$, $10 / 26$ and $35.7 \%, 5 / 14)$, anemia $(34.6 \%, 9 / 26$ and $35.7 \%$, $5 / 14)$, viral upper respiratory tract infection $(30.8 \%, 8 / 26$ and $64.3 \%, 9 / 14)$, and hypertension $(30.8 \%, 8 / 26$ and $35.7 \%$, $5 / 14)$. The grade $\geq 3$ AEs with the highest frequency were anemia $(26.9 \%, 7 / 26$ and $21.4 \%, 3 / 14)$, neutrophil count decreased (19.2\%, 5/26 and 0), pneumonia (15.4\%, 4/26 and $7.1 \%, 1 / 14)$, neutropenia $(15.4 \%$ and $7.1 \%)$, tumor lysis $(15.4 \%$ and 0$)$, and hypertension $(11.5 \%, 3 / 26$ and $14.3 \%$, $2 / 14)$. 
Table 2 Summary of efficacy results of the Japanese subgroup of the A.R.R.O.W. study

\begin{tabular}{|c|c|c|}
\hline & $\begin{array}{l}\text { Once-weekly } \\
\mathrm{Kd} 20 / 70 \mathrm{mg} / \mathrm{m}^{2} \\
(N=26)\end{array}$ & $\begin{array}{l}\text { Twice-weekly } \\
\text { Kd 20/27 mg/m } 2 \\
(N=14)\end{array}$ \\
\hline \multicolumn{3}{|l|}{ Best overall response, $n(\%)^{a}$} \\
\hline $\begin{array}{l}\text { Stringent complete response } \\
\text { (sCR) }\end{array}$ & $0(0.0)$ & $0(0.0)$ \\
\hline Complete response (CR) & $3(11.5)$ & $0(0.0)$ \\
\hline $\begin{array}{l}\text { Very good partial response } \\
\text { (VGPR) }\end{array}$ & $8(30.8)$ & $4(28.6)$ \\
\hline Partial response (PR) & $8(30.8)$ & $4(28.6)$ \\
\hline Minimal response (MR) & $3(11.5)$ & $0(0.0)$ \\
\hline Stable disease & $0(0.0)$ & $5(35.7)$ \\
\hline Progressive disease & $1(3.8)$ & $1(7.1)$ \\
\hline Not evaluable (NE) & $3(11.5)$ & $0(0.0)$ \\
\hline \multicolumn{3}{|l|}{ Duration of response ${ }^{b}$} \\
\hline Number of events, $n(\%)$ & $8(30.8)$ & $3(21.4)$ \\
\hline Median $(95 \%$ CI $)(\text { months })^{\mathrm{a}}$ & $15.1(11.1, \mathrm{NE})$ & $\mathrm{NE}(2.8, \mathrm{NE})$ \\
\hline \multicolumn{3}{|l|}{ Clinical benefit rate $(C B R)^{c}$} \\
\hline $\begin{array}{l}\text { Number of subjects who } \\
\text { achieved clinical benefit }\end{array}$ & 22 & 8 \\
\hline CBR $(95 \%$ CI $)(\%)^{\mathrm{d}}$ & $84.6(65.1,95.6)$ & $57.1(28.9,82.3)$ \\
\hline \multicolumn{3}{|l|}{ Overall survival } \\
\hline $\begin{array}{l}\text { Number of subjects who died, } \\
n(\%)\end{array}$ & $3(11.5)$ & $1(7.1)$ \\
\hline Median $(95 \%$ CI $)$ (months) $)^{\mathrm{e}}$ & $\mathrm{NE}(\mathrm{NE}, \mathrm{NE})$ & $\mathrm{NE}(\mathrm{NE}, \mathrm{NE})$ \\
\hline
\end{tabular}

Stratification factors: ISS stage at study entry (Stage 1 vs. Stage 2 or 3), refractory to bortezomib treatment (yes vs. no), and age $(<6$ vs. $\geq 65$ years)

$C I$ confidence interval, $K d$ carfilzomib (Kyprolis) plus dexamethasone, $N E$ not estimable

${ }^{a}$ Best overall response is defined as a subject's best response during the study

${ }^{\mathrm{b}}$ Median and percentiles were estimated using the Kaplan-Meier method. Corresponding CIs were estimated using the method by Klein and Moeschberger (1997) with log-log transformation

${ }^{\mathrm{c}}$ Clinical benefit is defined as achieving a best overall response of MR, PR, VGPR, CR or SCR

${ }^{\mathrm{d}}$ Clopper-Pearson interval

${ }^{\mathrm{e}}$ Median was estimated using the Kaplan-Meier method. Corresponding CIs were estimated using the method by Klein and Moeschberger (1997) with $\log -\log$ transformation

\section{Discussion}

The main objectives of this subgroup analysis were to examine the efficacy and safety of once-weekly and twice-weekly $\mathrm{Kd}$ regimens in the Japanese subgroup of the A.R.R.O.W. study population [13]. Additionally, we conducted an exploratory unadjusted analysis to compare the present results with those of a subgroup of patients from ENDEAVOR [7, 8].

The main efficacy findings of this analysis were that once-weekly $\mathrm{Kd} 20 / 70 \mathrm{mg} / \mathrm{m}^{2}$ tended to improve median
PFS (14.8 months) and ORR (73.1\%, 19/26) compared with the PFS (9.7 months) and ORR $(57.1 \%, 8 / 14)$ with the twice-weekly Kd 20/27 mg/m² regimen in Japanese RRMM patients. Furthermore, the ORR for both the once-weekly Kd $20 / 70 \mathrm{mg} / \mathrm{m}^{2}$ and twice-weekly $\mathrm{Kd} 20 / 27 \mathrm{mg} / \mathrm{m}^{2}$ regimens tended to be comparable to those observed in the interim analysis of A.R.R.O.W [13]. and to those observed with the once-weekly $\mathrm{Kd} 20 / 70 \mathrm{mg} / \mathrm{m}^{2}$ administration in the phase 1/2 CHAMPION-1 study (ORR $=77 \%, 80 / 104)$ [11] and a Japanese study using Kd weekly dosing in a similar patient population $(83.3 \%, 5 / 6)$ [12].

Regarding the safety profile of the Japanese subgroup from A.R.R.O.W., the overall incidence of grade $\geq 3$ AEs was comparable between the once-weekly Kd $20 / 70 \mathrm{mg} / \mathrm{m}^{2}$ $(80.8 \%, 21 / 26)$ and twice-weekly $\mathrm{Kd} 20 / 27 \mathrm{mg} / \mathrm{m}^{2}$ (78.6\%, $11 / 14$ ) arms. However, higher rates of carfilzomib treatment discontinuation, dose reduction, serious AEs, and fatal AEs were reported for once-weekly $\mathrm{Kd} 20 / 70 \mathrm{mg} / \mathrm{m}^{2}$ compared with twice-weekly $\mathrm{Kd} 20 / 27 \mathrm{mg} / \mathrm{m}^{2}$. Those higher ratios observed in the once-weekly $\mathrm{Kd} 20 / 70 \mathrm{mg} / \mathrm{m}^{2}$ arm were most likely attributed to the different evaluation periods: median durations of the study drug administration in the Japanese subgroups were 55.8 weeks in the once-weekly $\mathrm{Kd} 20 / 70 \mathrm{mg} / \mathrm{m}^{2}$ arm and 37.3 weeks in the twice-weekly $\mathrm{Kd} 20 / 27 \mathrm{mg} / \mathrm{m}^{2} \mathrm{arm}$. As compared to Japanese patients treated with the twice-weekly $\mathrm{Kd} 20 / 56 \mathrm{mg} / \mathrm{m}^{2}$ for 154 days in the ENDEAVOR study, Japanese patients treated with the once-weekly $\mathrm{Kd} 20 / 70 \mathrm{mg} / \mathrm{m}^{2}$ for the same 154-day period exhibited similar incidences of AEs, including AEs with grade 3 or more, fatal AEs, serious AEs, and AEs leading to treatment discontinuation. Therefore, incidence rates of these AEs during a particular period in the once-weekly Kd $20 / 70 \mathrm{mg} / \mathrm{m}^{2}$ arm may be comparable to those with the other treatments.

Two fatalities occurred in the once-weekly Kd arm; one fatality due to ALI and the other due to ARDS. Notably, such events occurred only in the Japanese subgroup. Unfortunately, the details and information regarding the ALI case were limited. However, the patient who presented ARDS had an underlying respiratory condition (pneumonia secondary to influenza virus) that may have predisposed the patient to develop respiratory complications. Regarding cardiac failure in relation to carfilzomib treatment, no fatal cardiac failure event was reported in Japanese patients, but two (7.7\%, $2 / 26)$ and one $(7.1 \%, 1 / 14)$ grade 3 or higher cardiac failure events were reported in the once-weekly and twice-weekly arms, respectively. One patient in the Japanese subgroup from A.R.R.O.W. receiving once-weekly Kd 20/70 mg/m ${ }^{2}$ presented TMA. Furthermore, TMA was also reported in the phase 1 study that assessed the tolerability of $\mathrm{Kd} 20 / 70 \mathrm{mg} /$ $\mathrm{m}^{2}$ in Japanese patients [12]. Although the occurrence of TMA is infrequent, once TMA occurs, it can become a serious event. Patients who develop TMA during carfilzomib 
Table 3 PFS and ORR of the once-weekly Kd 20/70 mg/m² arm in the Japanese subgroup from A.R.R.O.W. and twiceweekly $\mathrm{Kd} 20 / 56 \mathrm{mg} / \mathrm{m}^{2}$ in a subgroup from ENDEAVOR with two to three prior therapies, refractory to the most recent therapy, and prior proteasome inhibitor and immunomodulatory drugs

\begin{tabular}{|c|c|c|c|c|}
\hline & \multicolumn{2}{|c|}{$\begin{array}{l}\text { Once-weekly } \mathrm{Kd} 20 / 70 \mathrm{mg} / \mathrm{m}^{2} \\
\text { A.R.R.O.W }\end{array}$} & \multicolumn{2}{|c|}{$\begin{array}{l}\text { Twice-weekly Kd 20/56 mg/m² } \\
\text { ENDEAVOR }\end{array}$} \\
\hline & $n$ & Median PFS (95\% CI) & $\bar{N}$ & Median PFS (95\% CI) \\
\hline Overall population & 240 & $\begin{array}{l}11.3 \text { months } \\
(8.6-13.2)\end{array}$ & 464 & $\begin{array}{l}18.7 \text { months } \\
(15.6-\mathrm{NE})\end{array}$ \\
\hline
\end{tabular}

With two to three prior therapies, refractory to most recent therapy, and prior proteasome inhibitor and immunomodulatory drugs

$\begin{array}{cclll}\text { Yes } & 237 & \begin{array}{l}11.2 \text { months } \\ (8.6-13.0)\end{array} & 70 & \begin{array}{l}7.5 \text { months } \\ (3.7-10.2)\end{array} \\ \text { No } & 3 & \text { NE } & 394 & \begin{array}{l}22.2 \text { months } \\ (17.7-\mathrm{NE})\end{array} \\ \text { Japanese subgroup } & 26 & \begin{array}{l}14.8 \text { months } \\ (7.5-\mathrm{NE})\end{array} & 23 & \mathrm{NE}\end{array}$

With two to three prior therapies, refractory to most recent therapy, and prior proteasome inhibitor and immunomodulatory drugs

$\begin{array}{cllll}\text { Yes } & 26 & \begin{array}{l}14.8 \text { months } \\ (7.5-\mathrm{NE})\end{array} & 7 & \mathrm{NE} \\ \text { No } & & \text { N/A } & 16 & \text { NE } \\ & & \text { ORR }(95 \% \mathrm{CI}) & \text { Responder/ } n & \text { ORR }(95 \% \mathrm{CI}) \\ \text { Overall population } & 153 / 240 & 63.8 & 357 / 464 & 76.9 \\ & & (57.3-69.8) & & (72.8-80.7)\end{array}$

With 2-3 prior therapies, refractory to most recent therapy, and prior proteasome inhibitor and immunomodulatory drugs

$\begin{array}{cclll}\text { Yes } & 150 / 237 & 63.3 & 31 / 70 & 44.3 \\ & & (56.8-69.4) & & (32.4-56.7) \\ \text { No } & 3 / 3 & 100.0 & 326 / 394 & 82.7 \\ & & (29.2-100.0) & & (78.6-86.3) \\ \text { Japanese subgroup } & 19 / 26 & 73.1 & 18 / 23 & 78.3 \\ & & (52.2-88.4) & & (56.3-92.5)\end{array}$

With two to three prior therapies, refractory to most recent therapy, and prior proteasome inhibitor and immunomodulatory drugs

\begin{tabular}{|c|c|c|c|c|}
\hline Yes & $19 / 26$ & $\begin{array}{l}73.1 \\
(52.2-88.4)\end{array}$ & $3 / 7$ & $\begin{array}{l}42.9 \\
(9.9-81.6)\end{array}$ \\
\hline No & & N/A & $15 / 16$ & $\begin{array}{l}93.8 \\
(69.8-99.8\end{array}$ \\
\hline
\end{tabular}

$C I$ confidence interval, $K d$ carfilzomib (Kyprolis) plus dexamethasone, $N / A$ not applicable, $N E$ not evaluable, ORR overall response rate, $P F S$ progression-free survival treatment require careful attention and prompt management, including plasmapheresis, which may improve the outcome of these patients. Still, the present findings reinforce the need to closely monitor RRMM patients receiving $\mathrm{Kd}$ for ALI/ ARDS, cardiac failure, and TMA during treatment. Nonetheless, the overall benefit-risk profile of once-weekly $\mathrm{Kd}$ $20 / 70 \mathrm{mg} / \mathrm{m}^{2}$ was favorable among Japanese patients.

Exploratory analyses of the Japanese subgroup from the A.R.R.O.W. and ENDEAVOR studies (i.e., patients who had received two to three prior therapies, were refractory to the most recent therapy, and with prior use of a proteasome inhibitor and immunomodulatory drugs), suggested that the efficacy of carfilzomib (ORR 73.1\% [19/26] and 42.9\% [3/7] and median PFS 14.8 months and NE in the Japanese subgroups from A.R.R.O.W. and ENDEAVOR, respectively) tended to be similar between trials. Selected overall patient populations from A.R.R.O.W. and ENDEAVOR also showed comparable efficacy, consistently with a recent report [16]. As this was an exploratory comparison and not a head-to-head comparison, it is difficult to conclusively compare the clinical benefits of once weekly Kd 20/70 mg/ $\mathrm{m}^{2}$ and twice weekly $\mathrm{Kd} 20 / 56 \mathrm{mg} / \mathrm{m}^{2}$. In the ENDEAVOR trial, the median PFS of Asian patients was longer with $\mathrm{Kd}$ (14.9 months) than with Vd (8.8 months), and the ORR was $80.4 \%$ (45/56) vs. 70.2\% (40/57), respectively [17]. Similarly, the median PFS of Asian patients in A.R.R.O.W. was longer for once-weekly (16.0 months) than for twice-weekly dosing (8.4 months), and the ORR was $76.7 \%$ (23/30) compared with $53.3 \%(8 / 15)$, respectively [17].

A recent analysis of patient-reported outcomes comparing once-weekly $\mathrm{Kd} 20 / 70 \mathrm{mg} / \mathrm{m}^{2}$ and twice-weekly $\mathrm{Kd} 20 / 27 \mathrm{mg} / \mathrm{m}^{2}$ in the A.R.R.O.W. study in terms of 
Table 4 Overview of the incidence of adverse events of the Japanese subgroup of the A.R.R.O.W. study

\begin{tabular}{lll}
\hline & $\begin{array}{l}\text { Once-weekly Kd 20/70 mg/ } \\
\mathrm{m}^{2} \\
(N=26)\end{array}$ & $\begin{array}{l}\text { Twice-weekly } \\
\text { Kd 20/27 mg/ } \\
\mathrm{m}^{2} \\
(N=14)\end{array}$ \\
\hline All adverse events, $n(\%)$ & $26(100.0)$ & $14(100.0)$ \\
Grade $\geq 3$ & $21(80.8)$ & $11(78.6)$ \\
Serious adverse events & $16(61.5)$ & $4(28.6)$ \\
Leading to discontinuation of carfilzomib & $9(34.6)$ & $2(14.3)$ \\
Leading to discontinuation of dexamethasone & $9(34.6)$ & $2(14.3)$ \\
Fatal adverse events & $2(7.7)$ & $0(0.0)$ \\
Treatment-related adverse events ${ }^{a}, n(\%)$ & $24(92.3)$ & $13(92.9)$ \\
Grade $\geq 3$ & $21(80.8)$ & $9(64.3)$ \\
Serious adverse events & $16(61.5)$ & $2(14.3)$ \\
Leading to discontinuation of carfilzomib & $8(30.8)$ & $2(14.3)$ \\
Leading to discontinuation of dexamethasone & $9(34.6)$ & $2(14.3)$ \\
Fatal adverse events & $2(7.7)$ & $0(0.0)$ \\
\hline
\end{tabular}

Adverse events are defined as, for this reporting purpose, any adverse event with an onset date from the first dose through 30 days after the last dose of any study drug

Adverse events were coded using MedDRA version 20.0 and graded using NCI-CTCAE(version 4.03)

$K d$ carfilzomib (Kyprolis) plus dexamethasone

${ }^{a}$ Treatment-related adverse events are adverse events considered related to at least one study drug by the investigator, including those with unknown relationship convenience, satisfaction, and health-related quality of life of RRMM patients [18] described that patients in the once-weekly arm reported significantly greater convenience (odds ratio [OR], 4.98; 95\% CI 2.54-9.77; $p<0.001$ ) and satisfaction (OR, 2.41; 95\% CI $0.97-6.01 ; p=0.059$ ) than those in the twice-weekly arm. Furthermore, the time to deterioration was longer for those in the once-weekly arm compared with the twice-weekly arm. Thus, the present findings and those of the above report further support the convenience of the once-weekly regimen (studied in A.R.R.O.W.).

\section{Limitations}

The main limitations of the study were the small sample of Japanese patients and the open-label design. Additionally, selection bias could not be avoided. As the number of patients in the Japanese cohort is small, the efficacy and safety data should be considered as purely descriptive, and limited conclusions can be drawn from comparing individual AEs. Furthermore, the cross-trial comparison with ENDEAVOR [7] was an exploratory comparison, not a head-to-head comparison, and it was not adjusted. While we are aware of the limitations of this type of comparison, we considered this analysis would be of value as there are limited published data from clinical trials comparing onceweekly $\mathrm{Kd} 20 / 70 \mathrm{mg} / \mathrm{m}^{2}$ and twice-weekly $\mathrm{Kd} 20 / 56 \mathrm{mg} / \mathrm{m}^{2}$, both of which have been approved in Japan.

\section{Conclusions}

In the Japanese subgroup of the A.R.R.O.W. study, the onceweekly $\mathrm{Kd} 20 / 70 \mathrm{mg} / \mathrm{m}^{2}$ regimen tended to improve PFS and ORR compared with the twice-weekly Kd 20/27 mg/ $\mathrm{m}^{2}$ regimen. Regarding the safety profile of both regimens, higher rates of treatment discontinuation, dose reduction, and serious AEs were reported in the once-weekly $\mathrm{Kd}$ arm vs. the twice-weekly arm. Exploratory analyses comparing the once-weekly $\mathrm{Kd}$ regimen used in A.R.R.O.W. (Kd $20 / 70 \mathrm{mg} / \mathrm{m}^{2}$ ) and the twice-weekly $\mathrm{Kd}$ regimen used in ENDEAVOR (Kd $20 / 56 \mathrm{mg} / \mathrm{m}^{2}$ ) suggested that while total exposure (weekly carfilzomib dosage) was lower with the once-weekly regimen, its efficacy was consistent with the twice-weekly regimen. Thus, the results observed in the Japanese subgroup are consistent with those observed in the overall A.R.R.O.W. (Asia Pacific, Europe, and North America) and the ENDEAVOR subgroup who met the following criteria: had two to three prior therapies, were refractory to the most recent therapy and had prior use of a proteasome inhibitor and immunomodulatory drug (Europe, North America, South America, and the Asia-Pacific region). The present findings indicate that the $\mathrm{Kd}$ once-weekly regimen may be a convenient and favorable treatment option for Japanese RRMM patients. 
Table 5 Adverse events overall and grade $\geq 3$ occurring in more than $10 \%$ of subjects among the Japanese subgroup of the A.R.R.O.W. study

\begin{tabular}{|c|c|c|c|c|}
\hline \multirow[b]{3}{*}{ Preferred term } & \multicolumn{4}{|c|}{ Carfilzomib plus dexamethasone } \\
\hline & \multicolumn{2}{|c|}{$\begin{array}{l}\text { Once-weekly } \\
20 / 70 \mathrm{mg} / \mathrm{m}^{2} \\
(N=26)\end{array}$} & \multicolumn{2}{|c|}{$\begin{array}{l}\text { Twice-weekly } \\
20 / 27 \mathrm{mg} / \mathrm{m}^{2} \\
(N=14)\end{array}$} \\
\hline & All grades & Grade $\geq 3$ & All grades & Grade $\geq 3$ \\
\hline \multicolumn{5}{|l|}{ Hematological } \\
\hline Platelet count decreased & $10(38.5)$ & $2(7.7)$ & $5(35.7)$ & $2(14.3)$ \\
\hline Anemia & 9 (34.6) & $7(26.9)$ & $5(35.7)$ & $3(21.4)$ \\
\hline Neutrophil count decreased & 7 (26.9) & $5(19.2)$ & $0(0.0)$ & $0(0.0)$ \\
\hline Thrombocytopenia & $5(19.2)$ & $2(7.7)$ & $2(14.3)$ & $1(7.1)$ \\
\hline Neutropenia & $5(19.2)$ & $4(15.4)$ & $1(7.1)$ & $1(7.1)$ \\
\hline Lymphocyte count decreased & $4(15.4)$ & $2(7.7)$ & $3(21.4)$ & $1(7.1)$ \\
\hline White blood cell count decreased & $4(15.4)$ & $2(7.7)$ & $2(14.3)$ & $1(7.1)$ \\
\hline \multicolumn{5}{|l|}{ Non-hematological } \\
\hline Pyrexia & $11(42.3)$ & $0(0.0)$ & $1(7.1)$ & $0(0.0)$ \\
\hline Viral upper respiratory tract infection & $8(30.8)$ & $0(0.0)$ & $9(64.3)$ & $0(0.0)$ \\
\hline Hypertension & $8(30.8)$ & $3(11.5)$ & $5(35.7)$ & $2(14.3)$ \\
\hline Insomnia & $6(23.1)$ & $0(0.0)$ & $5(35.7)$ & $0(0.0)$ \\
\hline Muscle spasms & $4(15.4)$ & $0(0.0)$ & $1(7.1)$ & $0(0.0)$ \\
\hline Cough & $4(15.4)$ & $0(0.0)$ & $0(0.0)$ & $0(0.0)$ \\
\hline Hepatic function abnormal & $5(19.2)$ & $1(3.8)$ & $1(7.1)$ & $0(0.0)$ \\
\hline Pneumonia & $5(19.2)$ & $4(15.4)$ & $2(14.3)$ & $1(7.1)$ \\
\hline Diarrhea & $5(19.2)$ & $0(0.0)$ & $2(14.3)$ & $0(0.0)$ \\
\hline Constipation & $4(15.4)$ & $0(0.0)$ & $4(28.6)$ & $0(0.0)$ \\
\hline Tumor lysis syndrome & $4(15.4)$ & $4(15.4)$ & $0(0.0)$ & $0(0.0)$ \\
\hline Pharyngitis & $3(11.5)$ & $1(3.8)$ & $2(14.3)$ & $0(0.0)$ \\
\hline Influenza & $3(11.5)$ & $1(3.8)$ & $1(7.1)$ & $0(0.0)$ \\
\hline Stomatitis & $3(11.5)$ & $0(0.0)$ & $1(7.1)$ & $0(0.0)$ \\
\hline Vomiting & $3(11.5)$ & $0(0.0)$ & $0(0.0)$ & $0(0.0)$ \\
\hline Decreased appetite & $3(11.5)$ & $1(3.8)$ & $0(0.0)$ & $0(0.0)$ \\
\hline Weight decreased & $3(11.5)$ & $1(3.8)$ & $1(7.1)$ & $0(0.0)$ \\
\hline Hypokalemia & $2(7.7)$ & $1(3.8)$ & $3(21.4)$ & $1(7.1)$ \\
\hline Cardiac failure & $2(7.7)$ & $2(7.7)$ & $2(14.3)$ & $1(7.1)$ \\
\hline Back pain & $2(7.7)$ & $0(0.0)$ & $2(14.3)$ & $0(0.0)$ \\
\hline Pruritus & $2(7.7)$ & $0(0.0)$ & $2(14.3)$ & $0(0.0)$ \\
\hline Hyperglycemia & $3(11.5)$ & $1(3.8)$ & $1(7.1)$ & $0(0.0)$ \\
\hline Hyperuricemia & $3(11.5)$ & $0(0.0)$ & $1(7.1)$ & $0(0.0)$ \\
\hline Edema peripheral & $1(3.8)$ & $0(0.0)$ & $2(14.3)$ & $0(0.0)$ \\
\hline Dysgeusia & $1(3.8)$ & $0(0.0)$ & $2(14.3)$ & $0(0.0)$ \\
\hline Vascular pain & $1(3.8)$ & $0(0.0)$ & $2(14.3)$ & $0(0.0)$ \\
\hline Weight increased & $0(0.0)$ & $0(0.0)$ & $2(14.3)$ & $1(7.1)$ \\
\hline Eczema asteatotic & $0(0.0)$ & $0(0.0)$ & $2(14.3)$ & $0(0.0)$ \\
\hline
\end{tabular}

Acknowledgements The authors wish to thank all study participants and their families and all study sites and investigators. We thank the contributions and critical review of the manuscript by Jiafen Shu and Anita Zahlten-Kuemeli (Amgen, Thousand Oaks), as well as that from Yutaro Ueno (Ono Pharmaceutical). We also acknowledge the statistical support of Toshiaki Ozaki (Ono Pharmaceutical, Osaka). The authors thank Keyra Martinez Dunn, MD of Edanz Medical Writing, for providing medical writing support, which was funded by Ono
Pharmaceutical through EMC K.K. in accordance with Good Publication Practice (GPP3) guidelines (https://www.ismpp.org/gpp3). This research was funded by Amgen Inc. and Ono Pharmaceutical. Ono Pharmaceutical supported this manuscript using the data provided by Amgen. 


\section{Compliance with ethical standards}

Conflict of interest Dr. N. Takezako, Dr. H. Handa, Dr. S. Ozaki, Dr. Ilseung Choi, Dr. T Miyamoto, and Dr. S. Hagiwara report grants and personal fees from Ono Pharmaceutical during the conduct of the study. Dr. T Miyamoto reports lecture fees from Bristol-Myers Squibb, Otsuka Pharmaceutical, MSD, Astellas Pharmaceutical, Astellas Amgen Pharmaceutical, Celgene, Abbvie Pharmaceutical, and Takeda Pharmaceutical. Dr. H. Shibayama reports grants and personal fees from Ono Pharmaceutical during the conduct of the study; grants from Astellas, Teijin, Shionogi, Taiho, Merck Sharp \& Dohme, and Sumitomo Dainippon; grants and personal fees from Eisai, Celgene, Takeda, Nippon Shinyaku, and Daiichi Sankyo; and personal fees from Novartis, Janssen, Chugai, Kyowa Kirin, Otsuka, Bristol-Myers Squibb, Pfizer, Fujimoto Pharmaceutical, AbbVie, and AstraZeneca outside the submitted work. Dr. K. Suzuki reports grants and personal fees from Ono Pharmaceutical during the conduct of the study; grants and personal fees from Bristol-Myers Squibb, Celgene, and Amgen; and personal fees from Janssen, Takeda, Novartis, Sanofi, and AbbVie outside the submitted work. Dr. H. Kosugi reports grants and personal fees from Ono during the conduct of the study; and personal fees from Chugai, Celgene, Novartis, Bioverative Japan, Merck Sharp \& Dohme, Takeda, Janssen, Japan Blood Products Organization, Bristol-Myers Squibb, and Ono Pharmaceutical outside the submitted work. Dr. M. Ri reports grants and personal fees from Ono Pharmaceutical during the conduct of the study; grants and personal fees from Celgene, Janssen, Takeda, Ono Pharmaceutical, Bristol-Myers Squibb, and Sanofi; and grants from Kyowa Kirin outside the submitted work. Dr. I. Sugiura reports no conflict of interest. Dr. S. Iida reports grants and personal fees from Ono Pharmaceutical during the conduct of the study; grants and personal fees from Takeda, Celgene, Janssen, Bristol-Myers Squibb, Daiichi Sankyo, Sanofi, and AbbVie; and grants from Merck Sharp \& Dohme, Gilead, and GlaxoSmithKline outside the submitted work.

\section{References}

1. Yamabe K, Inoue S, Hiroshima C. Epidemiology and burden of multiple myeloma in Japan: a systematic review. Value Health. 2015;18:A335-A766.

2. Tan D, Lee JH, Chen W, Shimizu K, Hou J, Suzuki K, et al. Recent advances in the management of multiple myeloma: clinical impact based on resource-stratification. Consensus statement of the Asian Myeloma Network at the 16th international myeloma workshop. Leuk Lymphoma. 2018;59:2305-17.

3. Kim K, Lee JH, Kim JS, Min CK, Yoon SS, Shimizu K, et al. Clinical profiles of multiple myeloma in Asia — an Asian myeloma network study. Am J Hematol. 2014;89:751-6.

4. McBride A, Klaus JO, Stockerl-Goldstein K. Carfilzomib: a second-generation proteasome inhibitor for the treatment of multiple myeloma. Am J Health Syst Pharm. 2015;72:353-60.

5. Kubiczkova L, Pour L, Sedlarikova L, Hajek R, Sevcikova S. Proteasome inhibitors-molecular basis and current perspectives in multiple myeloma. J Cell Mol Med. 2014;18:947-61.

6. Kyprolis ${ }^{\circledR}$. Japanese package insert (November 2019; Edition 1) https://www.info.pmda.go.jp/go/pack/4291433D1026_1_04/. Accessed May 2020.
7. Dimopoulos MA, Moreau P, Palumbo A, Joshua D, Pour L, Hájek $\mathrm{R}$, et al. Carfilzomib and dexamethasone versus bortezomib and dexamethasone for patients with relapsed or refractory multiple myeloma (ENDEAVOR): a randomised, phase 3, open-label, multicentre study. Lancet Oncol. 2016;17(27-38):10.

8. Dimopoulos M, Goldschmidt H, Niesvizky R, Joshua D, Chng WJ, Oriol A, et al. Carfilzomib or bortezomib in relapsed or refractory multiple myeloma (ENDEAVOR): an interim overall survival analysis of an open-label, randomised, phase 3 trial. Lancet Oncol. 2017;18:1327-37.

9. Iida S, Tobinai K, Taniwaki M, Shumiya Y, Nakamura T, Chou T. Phase I dose escalation study of high dose carfilzomib monotherapy for Japanese patients with relapsed or refractory multiple myeloma. Int J Hematol. 2016;104:596-604.

10. Iida S, Watanabe T, Matsumoto M, Suzuki K, Sunami K, Ishida T, et al. Carfilzomib monotherapy in Japanese patients with relapsed or refractory multiple myeloma: a phase 1/2 study. Cancer Sci. 2019;110:2924-32.

11. Berenson JR, Cartmell A, Bessudo A, Lyons RM, Harb W, Tzachanis D, et al. CHAMPION-1: a phase $1 / 2$ study of once weekly carfilzomib and dexamethasone for relapsed or refractory multiple myeloma. Blood. 2016;127:3360-8.

12. Maruyama D, Tobinai K, Chou T, Taniwaki M, Shumiya Y, Iida S. Weekly carfilzomib and dexamethasone in Japanese patients with relapsed or refractory multiple myeloma: a phase 1 and PK/ PD trial. Cancer Sci. 2018;109:3245-52.

13. Moreau P, Mateos MV, Berenson JR, Weisel K, Lazzaro A, Song K, et al. Once weekly versus twice weekly carfilzomib dosing in patients with relapsed and refractory multiple myeloma (A.R.R.O.W.): interim analysis results of a randomised, phase 3 study. Lancet Oncol. 2018;19:953-64.

14. Durie BG, Harousseau JL, Miguel JS, Bladé J, Barlogie B, Anderson $\mathrm{K}$, et al. International uniform response criteria for multiple myeloma. Leukemia. 2006;20:1467-73.

15. Rajkumar SV, Harousseau JL, Durie B, Anderson KC, Dimopoulos M, Kyle R, et al. Consensus recommendations for the uniform reporting of clinical trials: report of the International Myeloma Workshop Consensus Panel 1. Blood. 2011;117:4691-5.

16. Moreau P, Stewart KA, Dimopoulos M, Siegel D, Facon T, Berenson J, et al. Once-weekly (70 mg/m2) vs twice-weekly $(56 \mathrm{mg} / \mathrm{m} 2)$ dosing of carfilzomib in patients with relapsed or refractory multiple myeloma: A post hoc analysis of the ENDEAVOR, A.R.R.O.R, and CHAMPION-1 trials. Cancer Med. 2020;9:2989-96.

17. Dimopoulos MA, Moreau P, Iida S, Huang SY, Takezako N, Chng WJ, et al. Outcomes for Asian patients with multiple myeloma receiving once- or twice-weekly carfilzomib-based therapy: a subgroup analysis of the randomized phase 3 ENDEAVOR and A.R.R.O.W. Trials. Int J Hematol. 2019;110:466-73.

18. Moreau P, Kumar S, Boccia R, Iida S, Goldschmidt H, Cocks K, et al. Convenience, satisfaction, health-related quality of life of once-weekly $70 \mathrm{mg} / \mathrm{m} 2$ vs twice-weekly $27 \mathrm{mg} / \mathrm{m} 2$ carfilzomib (randomized A.R.R.O.W. study). Leukemia. 2019;33:2934-46.

Publisher's Note Springer Nature remains neutral with regard to jurisdictional claims in published maps and institutional affiliations. 